\title{
The Effect of an Axial Force on the Vibration of Hinged Bars
}

\author{
BX S. WODNOWSKY.KRXEGER:
}

It can be shown that the vibration of an extensible bax, carrying no transverse load and having the ends fixed at the supports, causes an axial tensile force with a period equal to the half-period of the vibration of the bar. This force modifies the process of the vibration to a nonlinear one and produces an increase of the froguancy of vibration according to the increase of the amplitude.

\section{NOACENCLA TURE}

The following nomenclature is usod in the peper:

\section{$l=$ length of bar}

$y=$ instantaneous deflection of any point $x$, of bar

$\mathcal{B}=$ Young's modulus of material

$A$ creoroctional ares of bur

BS $=E L \ldots$ Aexural rigidity of mar

$r=\sqrt{I / A}$ ralius of arration

$\beta=$ spring constant of supports of terr relative to axfal displace. ment

$S_{0}=$ initial arial tensile force of bar

$S_{1}=$ axial tonsile force due to deflention

$q=$ transverse losd per unit length

$t=$ limo

$\psi=$ a function of $t$ alone

$\mu$ as vibration nase per unit length of bar

$a=$ half amplitude of vibration

$\alpha=a / r$

(s) frequency in cadisna per sec

$n$ - pasitaive integers

$P_{n}=\frac{n^{2} r^{3} B}{l^{n}}=$ Euler's load of bar for buckling form with $n$ half waves

$P_{0}=-4 S_{0}=$ initial compressive lmad of lisar

\section{Vibration of Bings}

The usual theory of vibration of the bars is based on the assumption that ane end of the mar, being free to wons in an axial direction, an extentionbes deflection of the bar is obtsined. In technical practico we often have to deal with immovable end hingeo, or with Dinges conneeted wi th sopports in such a manner that, as the ends apprased each octber, a tennile force is produced in the bar which is proportional to the amount of that motion. In these cases the efioct of the axial furce on the procese of vibrathon must be investigsated. Further, we asoumo an initial tonsile foros and an extensibility of the bar. The deflection of the bar does not noed to be omsll in comparisan with its transwerso

1 Frankfort-an-Main, Germany. dimensioms; however, it must be small enough to tepresent the curvature of the delooted bar by the approximate exprosion $a^{2} y / 2 x^{3}$.

In the absence of trans rerse load, the deflection of the vibrating bar, Fig. 1, ia defined by the differential mquation.

$$
B \frac{\partial y^{d} y}{\partial x^{4}}=-\mu \frac{\partial y^{2}}{\partial t^{2}}+\left(S_{0}+S_{1}\right) \frac{\partial^{2} y}{\partial x^{2}}
$$

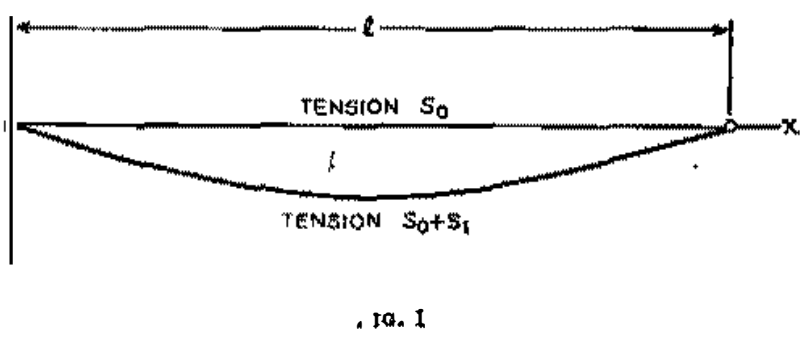

The value $S_{0}$ being given, we will first express the unknown force $S_{1}$ through the defootion $\psi$. The amount of apprason of both hinged ends of the bar due to the defleetion is

$$
\Delta l=\frac{1}{2} \int_{0}^{l}\left(\frac{\partial y}{\partial x}\right)^{x} d x
$$

Now, the arial force $S_{1}$ produces an elongation of the bar

$$
\Delta t=S_{1}\left(\frac{l}{E A}-\frac{1}{\beta}\right)=\frac{S i l}{E A}\left(1-\frac{E A}{l \beta}\right) \ldots \ldots
$$

It may bo seon from the last exprescion that the constarnt $1 / 0$ can be ornitted in our further imvortiontion without any loas of senerality. If, in fact, the sctusi constant 1/\% 0 , wa shouldonls replaco the actual area $A$ in our final resulta by the reduced valure

$$
A^{\prime}=\frac{4}{1-\frac{B A}{6 B}} \ldots \ldots \ldots \ldots \ldots \ldots \ldots \ldots
$$

Equaling now the Exprestions [2] and [3], we got

$$
S_{1}=k A \frac{\Delta t}{l}=\frac{B}{2 l s^{2}} \int_{0}^{t}\left(\frac{\partial y}{\partial x}\right)^{2} d x
$$

Substituting the last expereswion in Equation [1], we oblain

$$
\frac{\partial^{2} y}{\partial t^{2}}=-\frac{B}{\mu} \frac{\partial y}{\partial x^{2}}+\frac{1}{\mu}\left[S_{0}+\frac{B}{2 t x^{2}} \int_{0}^{t}\left(\frac{\partial y}{\partial x}\right)^{\prime} d x\right] \frac{\partial y}{\partial x x^{4}} \ldots \text { [6] }
$$

Futting

$$
y=a \psi \sin \frac{m x x}{l}, \ldots \ldots \ldots \ldots \ldots,[n]
$$

the gemotrical conditions at the Ninged ends of the bar are 
s*tisfied. Using Equation [6], we get the following equation for $\psi$

$$
\frac{d^{2} \psi}{d h^{2}}=-\frac{n^{4} \pi^{4} \alpha^{2} B}{4 \mu l \cdot} \psi^{4}-\left(\begin{array}{c}
n^{4} \pi^{4} B \\
\mu l^{4}
\end{array}+\frac{n^{2} \pi^{2} S_{0}}{\mu b^{2}}\right) \downarrow=\ldots[\mid 8]
$$

Multiplying this by $(2 \psi) /(d t)$ and integrating the result wo. twreen the maximusix deflection $(\psi=1,[d \psi] /[d i] \ldots 0)$ and any deflection $\psi$, we obrsin

$$
\left(\begin{array}{l}
d \psi \\
d l
\end{array}\right)^{2}=\frac{n^{4} \pi^{4} \alpha^{2} B}{8 \mu l^{4}}\left(1-\psi^{4}\right)+\left(\frac{n^{4} \pi^{4} B}{u l^{4}}+\frac{n^{2} \pi^{2} S_{0}}{\mu^{2}}\right)\left(1-\psi^{2} q_{1}\right.
$$

Using the sbbreviations

$$
p^{2}=\frac{n^{4} \pi^{4} B}{\mu^{4}}\left(1+\frac{\alpha^{2}}{1}\right)+\frac{n^{2} \pi^{3} S_{0}}{\mu l^{2}}
$$

\#nd

$$
k^{2}=\frac{1}{2+\frac{8}{a^{2}}\left(1+\frac{S_{d}^{2}}{n^{2} \pi^{2} B}\right)} \cdots \ldots \ldots \ldots . \mid 111
$$

Equation' [9] becomes

$$
\left[\frac{d v}{d(p t)}\right]^{y}-\left(1-\psi^{*}\right)\left(k^{2} w^{*}+1-k^{*}\right)
$$

The solution of this equarton is

$$
\psi=c n\left[p\left(t+t_{Q}\right), k\right]
$$

where $k$ is the modulus of the elliptic function and $l_{0}$ a constant of integration, which we ram make zero. Now, by Equation [7], wech expression of the form

$$
y=a \sin \frac{n \pi z}{l} \operatorname{con}(p t, k) \ldots \ldots \ldots, \ldots \ldots
$$

with $n=1,2,3$, . is a poswible solution of Equation [1]. But this enuation is senlinear in $y$, and for this formal reason a superposition of any solutions of the form, Equation [14], is not prac tieable. The obvious mechanical resson for difficulty in obtaining a general solution of the problem is the coupling effect of axial forces resulting from eaeh particular solution of the form of Equation [14].

The period of the function $\operatorname{con}(p t, k)$ is

$$
4 R=4 \int_{0}^{x / 2} \frac{d \varphi}{\sqrt{1-k^{2} \sin ^{2} \varphi}}
$$

and the corrsyonding frequency

$$
\omega=\frac{x p}{2 K}
$$

In the absence of axial forces (we can get this asesurning $S_{0}=\theta, r-\infty$ and thus obtaining $\left.\alpha=0, k=0, K=r / 2\right)$ the frequency becomes

$$
\omega_{0}=p_{0} . .
$$

where $p_{0^{8}}=n^{4} \pi^{4} B / m l^{4}$. Comparing this well-known result with the caso in which the ends of the bar an Gred $\left(S_{1} \neq 0\right)$, but the initial axisal force is zero $\left(S_{\theta}=0\right)$, we have by Equation \{10]

$$
\omega \quad \frac{\infty}{\omega_{0}}=\frac{x}{2 K} \sqrt{1+\frac{\alpha^{*}}{4}} \text {. }
$$

The effect of the amplitude on the increase of the frequency is ween from Table 1.
TABLE 1 EFFECT OF AMPLITUDE ON INCREABE OF FREQUENCY

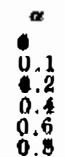

$0 / 00$
1.0008
1.0008
1.0038
1.015
1.038
1.058

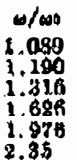

By Lquation [5] the tensile force due to the deflection alour is

Hence the frequency of this forot is equal to kes and its comximum value is

$$
\operatorname{auax} N_{1}=\frac{P_{n \alpha^{2}}}{4}
$$

$P_{n}$ being thas Eider losd which corresponds to the orthoguisal function $y=\operatorname{sim}\left(n_{\varepsilon x}\right) / l$.

We have now to eonsider the effest of the initial axial force $S_{4}$. At first let $S_{\mathrm{v}}$ be positive, by Equations [10] and [16] the frequency $w$ then increases if the value $S_{0}$ is increasing. Now lat $s_{s}$ become negative. While $S_{d}=P_{B}$ increases, the frequenciv w decreases, and it vanisbes if

$$
P_{1}=P_{\kappa}\left(1+\frac{m^{2}}{t}\right) \text {. }
$$

Consequently the critical value of the compresive force in a vibrating bar is larger than the Euler load $P_{n}$ when the deflection $i z$ zero, and it decreses to the value

$$
P=P_{\mathrm{B}}-\operatorname{mex} S_{\mathrm{R}}=P_{\mathrm{A}}
$$

at the instant of the maximum letleetion $(\psi-1)$. Until now, mo trangverse load on the bas was been sesumed. Treating the problem more rigorously, wo should intreduce at least a lood eommensurate to the mass of the bar. This load ann be replaced with sufficient accuracy by a tronswere load following the law

$$
q=\sin \frac{\pi x}{l}
$$

[ntroducing the lood $q$ in Equation [1], we ann reduce our froblem twe evaluation of an elliptic integral of the first laind

$$
\therefore=\int_{0}^{1} \frac{d \psi}{\sqrt{t}}
$$

where $\Psi$ deinotes a quadric in $\psi$. The inverse of this integral is wain an elliptic function. Contrary to the reault given in Equation [13], it would represent a noosymmetrias] vibaration about the axis $y=0$ of the undeflocted bar.

\section{Sordtion Beseex Furctions}

A swlution analogous to Equation (I4) can be obtainod, bý aeans of Besel functiono, for the csose of a vibratiog mincular plate with fixed edge, if the deferted surface of the plate is essumed a surface of revolution. However, sueb a solution would be of little practical intenst. In fact, if the amplitude of r.he vibration of the plate remsins amall, as compsrod with its thickness, the influence of the exterosl forces soting in the middlo plane can be practically neglected. Fowerar, if the dofleotions of the plate are cenmparable with its thicleneas, the well-known theory of bending of plates with large deflections must bo taken as the basis for furtber investigation, and the whole problem of vibrations then boosmes much more complimated. 